\title{
HABITS OF HIGHLY PRODUCTIVE INFORMATION SYSTEMS USERS: A LOOK AT ONE UNIVERSITY'S FACULTY, STAFF, AND STUDENTS
}

\author{
Gayle R. Jesse, West Liberty University, gayle.jesse@gmail.com \\ Lily J. Pharris, Northwestern State University of Louisiana, pharrisl@nsula.edu
}

\begin{abstract}
The adoption and use of information systems can help system users realize higher levels of productivity, but are people using systems in ways to help them achieve this aim? This paper explores the use of information systems and examines how stakeholders rank their productive use of technology. Four research questions were explored in order to delve deeper into the productivity of system users across a university campus, drilling down to the productivity of three underlying stakeholder groups: students, staff, and faculty. Furthermore, the study explores the breakdown of these three groups based on age and gender. The study found that, as a whole, West Liberty University is only $28 \%$ productive when using information systems. The study concludes with recommendations to educate the stakeholders on highly productive information systems habits. Finally, Steven Covey's Seven Habits of Highly Effective People is presented as a resource to help stakeholder groups become more productive information systems users.
\end{abstract}

Keywords: Information Systems (IS), Productivity Habits, Stakeholders, Technology, Steven Covey

\section{INTRODUCTION}

Individuals are exposed to vast amounts of data every day, data that needs to be collected and disseminated into useable information. Such data can be mined quickly with information systems like enterprise software, web applications (apps), and email. A study has shown people are strongly motivated to use smartphones and engage in social media (O'Donnell \& Epstein, 2019), and people may relate their smartphones and apps usage to personal productivity. The use of smartphones encourages multi-tasking, an activity one study has shown to cause distraction and decrease success (Karataş, 2018). Other studies have suggested that the use of information systems and related technologies has positive effects on performance (Han \& Yi, 2019); therefore, it is important to explore how individuals rank their productivity of information systems. This research paper will explore computer productivity among college students, staff, and faculty. Specifically, this study examined stakeholders' rank on productivity through use of information systems. Stakeholders were classified into four groups: total population, students, staff, and faculty.

\section{LITERATURE REVIEW}

Fundamentally, productivity measures how efficiently an organization transforms inputs to outputs (Laudon \& Laudon, 2017). Thus, to measure productivity related to an IS investment, productivity data must be collected and analyzed to determine the extent IS investments result in benefits at economic, industrial, organizational, and information systems application levels (Laudon \& Laudon, 2017; Brynjolfsson \& Yang, 1996). Measuring productivity gains in IS has been a challenge for business and industry, because the "returns of information technology investments should be analyzed within the competitive context of the firm, the industry, and the specific way in which information technology is being applied" (Laudon \& Laudon, 2017, p. 2). Moreover, U.S. businesses spend between 35 to 50 percent of overall capital outlays on information systems-related investments. Even so, while making an investment in technology can potentially improve worker productivity (Aral, Brynjolfsson, \& Van Alstyne, 2012), IS investments do not automatically guarantee organizational performance gains (Karr-Wisniewski $\& \mathrm{Lu}, 2010)$. This is especially true if the company fails to make corresponding investments in organizational structures, business processes, and organizational learning (Laudon \& Laudon, 2017). 


\section{Issues in Information Systems}

Volume 20, Issue 1, pp. 60-69, 2019

\section{Leveraging Technology for Productivity}

Karr-Wisniewski and $\mathrm{Lu}$ (2010) argue that people's technology use follows the law of diminishing marginal returns, a law suggesting people eventually get enough of a good thing. Thus, up to a certain point, people leverage information systems for greater productivity. However, once the optimal level of use has been reached, the marginal gain resulting from IS use begins to overwhelm the individual. The consequence of IS overuse results in technology overload, a term used to describe the phenomenon that exists "when additional technology tools begin to crowd out one's productivity instead of enhancing it" (Karr-Wisniewski \& Lu, 2010, p. 1061). The study by Karr-Wisniewski and $\mathrm{Lu}(2010)$ found evidence that three factors, information overload, communication overload, and system feature overload, contribute to technology-based productivity loss.

\section{Mobility}

Enhancements in information infrastructures and tools like cell phones, tablets, and laptops has resulted in more work being completed overall (Laudon \& Laudon, 2017). Still, though more work is being completed, this does not necessarily indicate productivity has increased. Rather, advancements in technology have removed the constraints of communication, giving people more control and flexibility over when and where they take care of work and personal tasks (Barley, Meyerson, \& Grodal, 2011). The gains in flexibility and control have resulted in blurred boundaries between work and home (Cecchinato, Cox, \& Bird, 2015). According to Towers, Duxby, Higgins, and Thomas (2006), some users embrace technology to maintain the balance between work and personal activities, while others see work steadily encroaching into personal boundaries. Though personal preferences come into play as to whether a person allows the work and home boundaries to blur or remain strictly separate, office norms and job roles also influence whether workers access work tasks during personal time (Cecchinato, Cox, \& Bird, 2015).

\section{Interruptions}

According to Jin and Dabbish (2009), information workers are interrupted as often as every 12 minutes. Nearly half of these interruptions come from external sources, and the other half occurs when workers interrupt themselves. Often, external interruptions start with the information systems people use to work. For example, many information systems use desktop alerts, which are designed to remind users about important tasks, events, or activities (Iqbal \& Horvitz, 2010). While users realize such features can disrupt their work, they still value the awareness that accompanies the disruption. Each interruption takes time to handle and recover from (Marulanda-Carter \& Jackson, 2012), and workers spend more time than they realize responding to such alerts (Iqbal \& Horvitz, 2007).

\section{Multitasking}

Technology has made switching tasks easier than ever before, but software does not as readily support users return to their primary activity following an interruption (Czerwinski, Horvitz, \& Wilhite, 2004). While mobile email users argue that devices allow them to be more responsive and engage in more effective multitasking (Middleton \& Cukier, 2006), other studies indicate multitasking reduces productivity rather than enhances it (Renaud, Ramsay, \& Hair, 2006). In studying task level practices at a recruiting firm, Aral, Brynjolfsson, and Van Alstyne (2007) found that higher amounts of multitasking was linked with declining project completion rates. The same study showed that those individuals who spent more time multitasking also brought in less revenue overall than their peers.

\section{Social media}

Research suggests people benefit socially and emotionally when engaging on online social media sites (Ellison, Steinfield, \& Lampe, 2007). Mark, Iqbal, Czerwinski, and Johns (2014) learned that both online and offline interactions influence the overall mood of employees at the office. Where email is more often tied to negative moods and multitasking makes people feel challenged and engaged, social media use contributes to a more positive employee disposition (Mark et al., 2014). Mark, Wang, and Niiya (2014) corroborated the findings of the Mark et al. (2014) study while examining the effect of multitasking on college students. The study showed students experienced lower stress levels when they spent more time on social media sites. The results contrasted with other associations in the study, revealing as students spent more time online, the more they experienced higher stress.

\section{Technology Adoption in the Workplace}

Organizations invest in technology to reduce costs and improve the quality of their products and services--areas that are not always easy to measure in terms of productivity (Brynjolfsson \& Yang, 1996). Still, before any cost reductions or quality improvements can occur, users of the workplace must adopt the technology. According to Davis (1989), for users to willingly accept and adopt a new technology, they need to perceive that the usefulness and 


\section{Issues in Information Systems}

Volume 20, Issue 1, pp. 60-69, 2019

ease of use of the product is worth changing the status quo. Over time it has become more feasible for organizations to install products containing numerous and complex features that make the software hard to use (Thompson, Hamilton, \& Rust, 2005). Additionally, how people use the tools and features of the device or software is sometimes unanticipated and may further contribute to feelings of technology overload experienced by employees (Ducheneaut \& Bellotti, 2001; Rennecker \& Godwin, 2005).

\section{Overcoming technology overload}

Organizations "acquire, design, and implement search engines, information agents, and information customization software" to help employees combat information overload (Farhoomand \& Drury, 2002, p. 128). Nonetheless, for an IT investment to produce greater worker productivity, it is necessary for the technology to support the tasks a person needs to perform (Goodhue \& Thompson, 1995). Many workers attempt to regain their productivity by embracing low-tech methods to help avoid experiencing technology overload (Karr-Wisniewski \& Lu, 2010). Carr and $\mathrm{Lu}$ (2007) suggest that organizations could benefit from investing in lighter versions of software rather than purchasing more complex, bloated software products where the excessive features incumber worker productivity. Research also advocates increasing the amount of training received by software users to help them feel more comfortable using the available features, thus allowing them to utilize the technology more effectively (Boothby, Dufour, \& Tang, 2010; Wood \& Neal, 2007; Dabbish \& Kraut, 2006; Bartel, 1994).

\section{METHODOLOGY}

\section{Research Design}

This explanatory study was designed utilizing quantitative methods with an objective approach. Three phases were used to conduct this quantitative study. The first phase consisted of developing a survey instrument, which was found in a Management Information Systems course textbook. The second phase included piloting the survey with someone not affiliated with West Liberty. Piloting the survey both confirmed the wording of survey questions was clear and established the time needed to complete the survey. Finally, the third phase involved survey distribution to the West Liberty University population using SurveyMonkey and West Liberty Gmail. Microsoft Excel was then used to prepare the statistics and graphs presented in the report findings.

\section{Participants}

This study used convenience sampling to target the population of West Liberty University located in West Liberty, West Virginia. The survey was distributed to the entire West Liberty population, including faculty, staff, and students. The participation statistics are as follows: Students 126 (2222), Staff 50 (166), and Faculty 54 (142). The response rate was approximately students $6 \%$, staff $30 \%$, and faculty $38 \%$. Overall, campus response rate was $11 \%$ of the total population. Resulting in a $95 \%$ confidence with a $6 \%$ margin of error.

\section{Survey Distribution}

Survey participants volunteered to respond by clicking on a SurveyMonkey link distributed via three e-mails sent by the researcher. Participants were at least 18 years old and either a Student, Staff, or Faculty member at West Liberty University. Since all the participants attend West Liberty, a true representation of the population is reflected.

\section{Survey Instrument}

The survey was accessible through a SurveyMonkey.com link, and the survey instrument designed for this investigation was comprised of both validated questions (Wallace, 2015, p.21) and non-validated questions (author created). Non-validated questions included demographic questions and questions used to categorize the participant as faculty, staff, student, or CIS student. The initial survey was divided into the following four sections: Consent Form; Demographic Information; Survey Questions and Closing/Thank You. The main survey contained 10 questions using the following Likert scale: $1=$ Not at all true for me, 2, 3, 4, 5, 6, 7 = Very true for me. To calculate the overall productivity score, response scores for all questions except 4 and 6 were tallied together to produce the first sub-score. For questions 4 and 6 , the response score value was reversed, such that 1 point would be assigned if the participant selected 7,2 points for 6, and so on. A second sub-score resulted from adding the new reversed score values for questions 4 and 6 . From there, the first and second sub-scores were added together to produce the overall productivity score of the participant. Overall productivity scores higher than 50 signifies a participant employs good habits associated with high productivity, including their use habits related to information systems. 


\section{RESEARCH QUESTIONS}

The literature review indicates that a noteworthy amount of research exists on the productivity of workers. However, is the creation of these numerous Information Systems (IS), software, social media, email, etc. helping society to be more productive by being able to streamline or multitask better than before the creation of these IS? With these numerous IS available, does society even know how to use all of this technology to its fullest potential? This study had two objectives: determine as whole the percentage of a university population that is considered to have habits of highly productive people and to determine the statistics of each type of group (student, staff, faculty) within a university. The Literature Review gathered as much pertinent information on other studies conducted in this area; which therefore offered insights in developing the following four Research Questions (RQs).

\section{Research Questions}

The purpose of this study was to explore computer productivity among college students, staff, and faculty. The four research questions to be answered were:

RQ1: How do West Liberty University (WLU) stakeholders (students, staff, \& faculty) rank on productivity when using information systems?

RQ2: How do WLU students rank on productivity when using information systems?

RQ3: How does WLU staff rank on productivity when using information systems?

RQ4: How does WLU faculty rank on productivity when using information systems?

\section{DATA ANALYSIS}

Microsoft Excel was used to calculate the percentage-based statistics reported in this study; all results exclude the system missing responses. Appendix A contains the demographic statistics of age, race, gender, university stakeholders (students, staff, faculty), and CIS students reported in 2018 from West Liberty University (WLU).

\section{FINDINGS}

This study provided practical insights for the field of computer information systems by exploring if a university is productive using technology or using it the fullest potential. As previously stated, the statistical survey findings were determined by calculating the percentage. The four research questions in this exploratory study found the following statistics and cross tabulations were created to show the variable "High Productivity" results based on Age, Gender (Female \& Male), and Stakeholder Type (Students, Staff, \& Faculty).

RQ1: University Productivity

Finding: $27.78 \%$

Table 1. University as whole percentage statistics for stakeholder type, gender, age with high productivity habits

\begin{tabular}{|r|c|}
\hline \multicolumn{2}{|c|}{ University by Stakeholder } \\
\hline All Types & $27.78 \%$ \\
\hline Student & $6.11 \%$ \\
\hline CIS Students & $0.56 \%$ \\
\hline Staff & $12.78 \%$ \\
\hline Faculty & $8.33 \%$ \\
\hline
\end{tabular}

\begin{tabular}{|r|c|}
\hline \multicolumn{2}{|c|}{ University by Gender } \\
\hline Female & $16.67 \%$ \\
\hline Male & $10.56 \%$ \\
\hline
\end{tabular}

\begin{tabular}{|r|c|}
\hline \multicolumn{2}{|c|}{ University by Age } \\
\hline 18 & $0.56 \%$ \\
\hline 19 & $1.67 \%$ \\
\hline 20 & $1.11 \%$ \\
\hline 21 & $1.11 \%$ \\
\hline 22 & $0.56 \%$ \\
\hline $23-29$ & $2.22 \%$ \\
\hline $30-39$ & $6.11 \%$ \\
\hline $40-49$ & $4.44 \%$ \\
\hline $50-59$ & $6.11 \%$ \\
\hline $60-69$ & $3.89 \%$ \\
\hline $70+$ & $0.00 \%$ \\
\hline
\end{tabular}


RQ2: Student Productivity

Finding: $10.28 \%$

Table 2. Cross tabulation of Students with high productivity habits

\begin{tabular}{|r|c|c|c|c|c|}
\hline \multicolumn{1}{|c|}{ Age } & Female & Male & (null) & Total Count & Total Percent \\
\hline 18 & & 1 & & $\mathbf{1}$ & $\mathbf{9 . 0 9 \%}$ \\
\hline 19 & 2 & 1 & & $\mathbf{3}$ & $\mathbf{1 1 . 5 4 \%}$ \\
\hline 20 & 1 & 1 & & $\mathbf{2}$ & $\mathbf{1 2 . 5 0 \%}$ \\
\hline 21 & 1 & & 1 & $\mathbf{2}$ & $\mathbf{7 . 6 9 \%}$ \\
\hline 22 & & 1 & & $\mathbf{1}$ & $\mathbf{1 1 . 1 1 \%}$ \\
\hline $23-29$ & 1 & 2 & & $\mathbf{3}$ & $\mathbf{1 8 . 7 5 \%}$ \\
\hline Total Count & $\mathbf{5}$ & $\mathbf{6}$ & $\mathbf{1}$ & $\mathbf{1 2}$ & \\
\hline Total Percent & $\mathbf{5 . 8 8 \%}$ & $\mathbf{1 5 . 0 0 \%}$ & & & \\
\hline
\end{tabular}

RQ3: Staff Productivity

Finding: 85.19\%

Table 3. Cross tabulation of Staff with high productivity habits

\begin{tabular}{|r|c|c|c|c|}
\hline \multicolumn{1}{|c|}{ Age } & Female & Male & Total Count & $\begin{array}{c}\text { Total } \\
\text { Percent }\end{array}$ \\
\hline $23-29$ & 1 & & $\mathbf{1}$ & $\mathbf{2 5 . 0 0 \%}$ \\
\hline $30-39$ & 5 & 2 & $\mathbf{7}$ & $\mathbf{5 0 . 0 0 \%}$ \\
\hline $40-49$ & 1 & 1 & $\mathbf{2}$ & $\mathbf{4 0 . 0 0 \%}$ \\
\hline $50-59$ & 6 & 2 & $\mathbf{8}$ & $\mathbf{4 4 . 4 4 \%}$ \\
\hline $60-69$ & 4 & 1 & $\mathbf{5}$ & $\mathbf{6 2 . 5 0 \%}$ \\
\hline Total Count & $\mathbf{1 7}$ & $\mathbf{6}$ & $\mathbf{2 3}$ & \\
\hline Total Percent & $\mathbf{4 8 . 5 7 \%}$ & $\mathbf{4 2 . 8 6 \%}$ & & \\
\hline
\end{tabular}

RQ4: Faculty Productivity

Finding: $38.46 \%$

Table 4. Cross tabulation of Faculty with high productivity habits

\begin{tabular}{|r|c|c|c|c|}
\hline \multicolumn{1}{|c|}{ Age } & Female & Male & Total Count & Total Percent \\
\hline $30-39$ & 2 & 2 & $\mathbf{4}$ & $\mathbf{3 6 . 3 6 \%}$ \\
\hline $40-49$ & 2 & 4 & $\mathbf{6}$ & $\mathbf{3 3 . 3 3 \%}$ \\
\hline $50-59$ & 3 & & $\mathbf{3}$ & $\mathbf{3 0 . 0 0 \%}$ \\
\hline $60-69$ & 1 & 1 & $\mathbf{2}$ & $\mathbf{1 6 . 6 7 \%}$ \\
\hline Total Count & $\mathbf{8}$ & $\mathbf{7}$ & $\mathbf{1 5}$ & $\mathbf{3 6 . 3 6 \%}$ \\
\hline Total Percent & $\mathbf{2 4 . 2 4 \%}$ & $\mathbf{3 3 . 3 3 \%}$ & & \\
\hline
\end{tabular}

Additional Findings: The following additional findings are based on the ten Survey Questions that were used determine the productivity score. The survey question along with only the highest percentages are noted.

1. I empty my email inbox every day. $\mathbf{2 8 . 7 \%}$ very true for me

2. I keep a to-do list, and always keep it up to date. $\mathbf{2 3 . 0 4 \%}$ very true for me

3. I use email filters to sort message by how important they are. $\mathbf{4 5 . 2 2 \%}$ not at all true for me

4. I stay logged into my social network most of the day, so I am alerted when updates occur, or message appear. $\mathbf{2 6 . 0 9 \%}$ very true for me

5. I rarely print anything out. $\mathbf{2 0 . 5 2 \%} \# 4$ on Likert scale

6. I send and receive text message very frequently, though most are unimportant. $\mathbf{2 1 . 7 4 \%}$ very true for me

7. I focus on the most important projects and can ignore distractions. $\mathbf{2 7 . 3 9 \%} \# 5$ on Likert scale 
8. I have a clear vision of what I want to achieve and make priorities. $\mathbf{3 2 . 7 5 \%}$ very true for me

9. I keep a calendar online rather than on paper, and I keep it up to date. $\mathbf{3 1 . 3 0 \%}$ not at all true for me

10. My electronic files are very well organized. For example: folders and sub-folders. $\mathbf{3 5 . 2 2 \%}$ very true for me

\section{DISCUSSION}

RQ1: How do West Liberty University stakeholders (students, staff, \& faculty) as a whole rank on productivity when using information systems? The responses indicated that $28 \%$ of the West Liberty population have habits that enhance their productivity. Data also yielded that females have good productivity habits at $17 \%$ and males at $11 \%$.

RQ2: How do WLU students rank on productivity when using information systems? When looking at the student population as a whole the responses indicated that about $7 \%$ out of $28 \%$ have good habits of productivity, which was the lowest out of the three stakeholder groups. Individually looking at the student population, we found that $10 \%$ of students have good productivity habits. Age range 23-29 was the best at $19 \%$, while age 21 was only $8 \%$. Males showed good productivity habits.

RQ3: How does WLU staff rank on productivity when using information systems? The staff at West Liberty University had the highest overall productivity habits out of the stakeholders. Staff are $13 \%$ out of the $28 \%$ of all stakeholder groups. Likewise, $85 \%$ of the staff population have good productivity habits. The age range of 60-69 had good productivity at $63 \%$, while age $23-29$ was $25 \%$. In this stakeholder group, we found that females showed good productivity habits.

RQ4: How does WLU faculty rank on productivity when using information systems? Faculty ended up being the middle group in terms of possessing good productivity habits. Given all the stakeholders, faculty were $8 \%$ of the $28 \%$. Faculty as a group had $38 \%$ good productivity habits. Age range $30-39$ had good productivity habits at $36 \%$, whereas age $60-69$ was only $17 \%$. Male faculty had good productivity habits.

\section{LIMITATIONS}

Even though a quantitative study can have many limitations, this discussion will focus on only one major limitation. The principal limitation of the study was that the study only collected quantitative data. More specifically, this quantitative study only required participants to respond to closed-ended questions. The use of a mixed methods approach offers the ability to produce a more accurate representation of the population, because, in addition to ranking their productivity on the Likert scale, participants can provide additional insights into why they selected a score. These insights could then be used to produce greater understanding about the differences between scoring. The final limitation involved the distribution of the survey. Only one university was studied; therefore, the results are not indicative of all universities. Future studies could be conducted at other universities to broaden the scope and acquire more indicative results.

\section{CONCLUDING REMARKS}

Conclusions of this exploratory research study found that over $28 \%$ of the University population has high productivity habits. Further research found that, between the three stakeholder groups, college students, staff, and faculty rank their high productivity habits at $10 \%, 85 \%$, and $38 \%$, respectively. These findings imply university staff is the most productive stakeholder. Overall, based on the $28 \%$ score, we learned that West Liberty might benefit from teaching all stakeholders about highly productive information systems habits. In addition, the results of this study should be used to inform information systems and university communities about the importance of providing and encouraging others to employ good habits to become highly productive using technology.

In writing this publication, the researchers examined Steven Covey's the Seven Habits of Highly Effective People as a potential resource to offer insights into the habits people need to develop to become highly productive information systems users. The researchers found Covey's bestselling book to provide applicable advice for learning institutions 


\section{Issues in Information Systems}

Volume 20, Issue 1, pp. 60-69, 2019

across the U.S. wishing to build productive user habits related to information systems. Indeed, these habits have the potential to enhance information systems use in life, career, and education. Steven Covey (1996) wrote that highly effective people should apply the following seven habits to how they live their life and grow in their career:

1. Be proactive,

2. Begin with the end in mind,

3. Put first things first,

4. Think win-win,

5. Seek first to understand, then to be understood,

6. Synergize, and

7. Sharpen their saws.

In 2013, Lacher stated, "Steven Covey, author of Seven Habits of Highly Effective People, points out that most of us spend our time working on urgent and (hopefully) important issues, but we should actually be concentrating on nonurgent important things. How do we make that happen?". Lacher raises the question--how do people concentrate on non-urgent important issues using information systems and remain productive? Moreover, Covey (1996) broke the habits into three (3) areas: self, team, and continued growth. Habits 1-3 center on self-mastery and moving from dependence to independence; habits 4-6 focus on the development of teamwork, collaboration, and communication skills, and moving from independence to interdependence; and finally, habit 7, which embodies the previous six habits, concentrates on continuous growth and improvement. In the current study, Covey's seven habits can be similarly applied to using information systems effectively; thus, paralleling the seven habits to the 10 survey questions within the three groups. Survey questions $1,3,4$, and 10 fit into the self category. Whereas, questions 5 , 7 , and 9 can be grouped into the team category. Finally, survey question 2 and 8 can be categorized as continued growth.

With this categorization of productivity habits, any organization could explore using Steven Covey's seven habits with stakeholders to more effectively use information systems. It is apparent that the demands of the world we live in "require us to take responsibility and initiative, have a focused sense of direction and mission, prioritize, work together, understand ourselves and others more clearly, tap into the power of creativity, and lead a flexible, balanced life and career" (Matejka, 1998). However, knowing is not enough. One must be willing to change behaviors and reinforce healthier habits. Poor habits, behaviors, and thinking could be holding us back from growing both individually and as an organization. As Jack Welch, CEO of GE, once said, "An organization's ability to learn, and translate that learning into action rapidly, is the ultimate competitive advantage."

\section{REFERENCES}

Aral, S., Brynjolfsson, E., \& Van Alstyne, M. (2007). Information, technology and information worker productivity: Task level evidence. Retrieved from http://www.nber.org/papers/w13172.pdf

Barley, S. R., Meyerson, D. E., \& Grodal, S. (2011). E-mail as a source and symbol of stress. Organization Science, 22(4), 887-906. Retrieved from https://www.jstor.org/stable/pdf/20868902.pdf

Bartel, A. P. (1994). Productivity gains from the implementation of employee training programs. Industrial relations: a journal of economy and society, 33(4), 411-425. Retrieved from https://www.nber.org/papers/w3893.pdf

Bautista, J. R., Rosenthal, S., Lin, T. T. C., \& Theng, Y. L. (2018). Predictors and outcomes of nurses' use of smartphones for work purposes. Computers in Human Behavior, 84, 360-374. doi:10.1016/j.chb.2018.03.008

Boothby, D., Dufour, A., \& Tang, J. (2010). Technology adoption, training and productivity performance. Research Policy, 39(5), 650-661. Retrieved from https://www.sciencedirect.com/science/article/abs/pii/S0048733310000594 


\section{Issues in Information Systems}

Volume 20, Issue 1, pp. 60-69, 2019

Brynjolfsson, E., \& Yang, S. (1996). Information technology and productivity: a review of the literature. Advances in Computers, 43, 179-214. Retrieved from http://citeseerx.ist.psu.edu/viewdoc/download?doi=10.1.1.84.5827\&rep=rep1\&type=pdf

Carr, P., \& Lu, Y. (2007). Information Technology and Knowledge Worker Productivity: A Taxonomy of Technology Crowding. AMCIS 2007 Proceedings, 51. Retrieved from https://pdfs.semanticscholar.org/1e3a/a14a453032a1a07991b1ce463a52478c395f.pdf

Cecchinato, M. E., Cox, A. L., \& Bird, J. (2015, April). Working 9-5?: Professional differences in email and boundary management practices. In Proceedings of the 33rd Annual ACM Conference on Human Factors in Computing Systems (pp. 3989-3998). ACM. Retrieved from http://nrl.northumbria.ac.uk/33668/1/p3989cecchinato.pdf

Covey, S. R. (1996). The seven habits of highly effective people: Overview. Provo, UT: Covey Leadership Center.

Czerwinski, M., Horvitz, E., \& Wilhite, S. (2004, April). A diary study of task switching and interruptions. In Proceedings of the SIGCHI conference on Human factors in computing systems (pp. 175-182). ACM. Retrieved from https://www.cs.drexel.edu/ salvucci/courses/cs680-s11/BK/readings/CzerwinskiCHI04.pdf

Dabbish, L. A., \& Kraut, R. E. (2006, November). Email overload at work: an analysis of factors associated with email strain. In Proceedings of the 2006 20th anniversary conference on Computer supported cooperative work (pp. 431-440). ACM. Retrieved from https://www.researchgate.net/profile/Robert_Kraut/publication/220879068_Email_overload_at_work_An_ analysis_of_factors_associated_with_email_strain/links/00b4952951e9293620000000.pdf

Davis, F. D. (1989). Perceived usefulness, perceived ease of use, and user acceptance of information technology. MIS Quarterly, 319-340. Retrieved from https://www.jstor.org/stable/pdf/249008.pdf

Ducheneaut, N., \& Bellotti, V. (2001). E-mail as habitat: an exploration of embedded personal information management. Interactions, 8(5), 30-38.

Edmunds, A., \& Morris, A. (2000). The problem of information overload in business organizations: a review of the literature. International journal of information management, 20(1), 17-28. Retrieved from http://citeseerx.ist.psu.edu/viewdoc/download?doi=10.1.1.203.3150\&rep=rep1\&type=pdf

Ellison, N. B., Steinfield, C., \& Lampe, C. (2007). The benefits of Facebook "friends:" Social capital and college students' use of online social network sites. Journal of Computer-Mediated Communication, 12(4), 11431168.

Farhoomand, A. F., \& Drury, D. H. (2002). Managerial Information Overload. Communications of the ACM, 45(10), 127-131. https://doi.org/10.1145/570907.570909

Goodhue, D. L., \& Thompson, R. L. (1995). Task-technology fit and individual performance. MIS quarterly, 213236. Retrieved from https://www.jstor.org/stable/pdf/249689.pdf

Han, S., \& Yi, Y. J. (2019). How does the smartphone usage of college students affect academic performance? Journal of Computer Assisted Learning, 35(1), 13-22. doi:10.1111/jcal.12306

Iqbal, S. T., \& Horvitz, E. (2007, April). Disruption and recovery of computing tasks: field study, analysis, and directions. In Proceedings of the SIGCHI conference on Human factors in computing systems (pp. 677686). ACM. Retrieved from

https://www.researchgate.net/profile/Shamsi_Iqbal/publication/221514976_Disruption_and_Recovery_of_ Computing_Tasks_Field_Study_Analysis_and_Directions/links/0c960517545490a816000000.pdf

Iqbal, S. T., \& Horvitz, E. (2010, February). Notifications and awareness: a field study of alert usage and preferences. In Proceedings of the 2010 ACM conference on Computer supported cooperative work (pp. 27-30). ACM. Retrieved from https://www.microsoft.com/en-us/research/wpcontent/uploads/2016/02/253n-iqbal.pdf 


\section{Issues in Information Systems}

Volume 20, Issue 1, pp. 60-69, 2019

Jin, J., \& Dabbish, L. A. (2009, April). Self-interruption on the computer: a typology of discretionary task interleaving. In Proceedings of the SIGCHI conference on human factors in computing systems (pp. 17991808). ACM.

Karataş, E. (2018). A case study on the positive effects of smartphone usage in postgraduate education. Bartin Üniversitesi Egitim Fakültesi Dergisi, 7(2), 607-634. doi:10.14686/buefad.402975

Karr-Wisniewski, P., \& Lu, Y. (2010). When more is too much: Operationalizing technology overload and exploring its impact on knowledge worker productivity. Computers in Human Behavior, 26(5), 1061-1072.

Lacher, E. (2014). 4 ways to stop being a perfectionist veterinarian. Veterinary Economics, 55(1).

Laudon, K. C., \& Laudon, J. P. (2017). Essentials of management information systems. Upper Saddle River: Pearson.

Mark, G., Iqbal, S. T., Czerwinski, M., \& Johns, P. (2014, April). Bored Mondays and focused afternoons: the rhythm of attention and online activity in the workplace. In Proceedings of the SIGCHI Conference on Human Factors in Computing Systems (pp. 3025-3034). ACM. Retrieved from https://www.microsoft.com/en-us/research/wp-content/uploads/2016/02/Focus20Camera-Ready20Final.pdf

Mark, G., Wang, Y., \& Niiya, M. (2014, April). Stress and multitasking in everyday college life: an empirical study of online activity. In Proceedings of the SIGCHI Conference on Human Factors in Computing Systems (pp. 41-50). ACM. Retrieved from https://www.ics.uci.edu/ gmark/Home_page/Publications_files/Millennial\%20CameraReady\%20Submission4.pdf

Marulanda-Carter, L., \& Jackson, T. W. (2012). Effects of e-mail addiction and interruptions on employees. Journal of Systems and Information Technology, 14(1), 82-94. Retrieved from https://interruptions.net/literature/Marulanda-Carter-JSystInformTech12.pdf

Matejka, K., Dunsing, R. J., \& Walat, B. (1998). The seven habits of highly defective people. Management Decision, 36(10), 654-656. doi:10.1108/00251749810245309

Middleton, C. A., \& Cukier, W. (2006). Is mobile email functional or dysfunctional? Two perspectives on mobile email usage. European Journal of Information Systems, 15(3), 252-260. Retrieved from https://www.tandfonline.com/doi/abs/10.1057/palgrave.ejis.3000614

O'Donnell, S., \& Epstein, L. H. (2019). Smartphones are more reinforcing than food for students. Addictive Behaviors, 90, 124-133. doi:10.1016/j.addbeh.2018.10.018

Renaud, K., Ramsay, J., \& Hair, M. (2006). " You've got e-mail!"... shall I deal with it now? Electronic mail from the recipient's perspective. International Journal of Human-Computer Interaction, 21(3), 313-332. Retrieved from http://web.b.ebscohost.com/ehost/detail/detail?vid=0\&sid=d42a2113-0943-4cd2-a561a133f6e6b313\%40sessionmgr101\&bdata=JnNpdGU9ZWhvc3QtbG12ZSZzY29wZT1zaXR1\#AN=2343117 $3 \& \mathrm{db}=\mathrm{bth}$

Rennecker, J., \& Godwin, L. (2005). Delays and interruptions: A self-perpetuating paradox of communication technology use. Information and Organization, 15(3), 247-266. Retrieved from https://interruptions.net/literature/Rennecker-I\&O05.pdf

Thompson, D. V., Hamilton, R. W., \& Rust, R. T. (2005). Feature fatigue: When product capabilities become too much of a good thing. Journal of marketing research, 42(4), 431-442. Retrieved from https://www.jstor.org/stable/pdf/30162393.pdf

Towers, I., Duxbury, L., Higgins, C., \& Thomas, J. (2006). Time thieves and space invaders: Technology, work and the organization. Journal of Organizational Change Management, 19(5), 593-618. Retrieved from https://www.mngt.waikato.ac.nz/ejrot/cmsconference/2005/proceedings/spaceandtime/Towers.pdf

Wallace, P. M. (2015). Introduction to information systems (pp. 21 and 31). Boston: Pearson.

Wood, W., \& Neal, D. T. (2007). A new look at habits and the habit-goal interface. Psychological review, 114(4), 843. Retrieved from 
https://www.researchgate.net/profile/Wendy_Wood2/publication/5936907_A_New_Look_at_Habits_and_t he_Habit-Goal_Interface/links/55b6f50f08ae092e9656f93b/A-New-Look-at-Habits-and-the-Habit-GoalInterface.pdf

\section{APPENDIX A}

1. What is your age?

$\quad$ Answer Choices
$<18$
18
19
20
21
22
$23-29$
$30-39$
$40-49$
$50-59$
$60-69$
$70+$

$\begin{array}{rr}\text { Responses } & \\ 0.00 \% & 0 \\ 4.82 \% & 11 \\ 11.40 \% & 26 \\ 7.02 \% & 16 \\ 11.84 \% & 27 \\ 3.95 \% & 9 \\ 8.33 \% & 19 \\ 15.79 \% & 36 \\ 11.84 \% & 27 \\ 14.47 \% & 33 \\ 9.21 \% & 21 \\ 1.32 \% & 3\end{array}$

Answered

Skipped

2. What is your gender?

\begin{tabular}{|l|cr}
\hline \multicolumn{1}{|c}{ Answer Choices } & \multicolumn{2}{c}{ Responses } \\
\hline Female & $66.81 \%$ & 153 \\
\hline Male & $33.19 \%$ & 76 \\
Other (specify) & $0.00 \%$ & 0 \\
Prefer not to answer & $0.00 \%$ & 0 \\
& Answered & $\mathbf{2 2 9}$ \\
& Skipped & $\mathbf{1}$
\end{tabular}

3. Are you White, Black or African-American, American Indian or Alaskan Native, Asian, Native Hawaiian or other Pacific Islander, or some other race?

\begin{tabular}{|lrr}
\multicolumn{1}{|c}{ Answer Choices } & \multicolumn{2}{c}{ Responses } \\
\hline White & $95.15 \%$ & 21 \\
Black or African-American & $1.32 \%$ & 3 \\
American Indian or Alaskan Native & $0.00 \%$ & 0 \\
Asian & $0.88 \%$ & 2 \\
Native Hawaiian or other Pacific & $0.00 \%$ & 0 \\
islander & $1.32 \%$ & 3 \\
From multiple races & $0.00 \%$ & 0 \\
Some other race (please specify) & $1.32 \%$ & 3 \\
Prefer not to answer & Answer & $\mathbf{2 2}$ \\
& ed & $\mathbf{7}$ \\
& Skipped & $\mathbf{3}$
\end{tabular}

4. Are you a Student, Staff, or Faculty member at WLU? Select one of the following.

\begin{tabular}{l|rr}
\multicolumn{1}{c}{ Answer Choices } & Responses \\
Student & $54.78 \%$ & 126 \\
Staff & $21.74 \%$ & 50 \\
Faculty & $23.48 \%$ & 54 \\
& Answered & $\mathbf{2 3 0}$ \\
& Skipped & $\mathbf{0}$
\end{tabular}

5. If you are a student, are you a CIS major or minor?

\begin{tabular}{|lrr}
\multicolumn{1}{c}{ Answer Choices } & \multicolumn{2}{c}{ Responses } \\
Yes & $5.52 \%$ & 8 \\
No & $94.48 \%$ & 137 \\
Considering a CIS major & $0.00 \%$ & 0 \\
& Answered & $\mathbf{1 4 5}$ \\
& Skipped & $\mathbf{8 5}$
\end{tabular}

